\title{
11 \\ COMPARISON OF THREE DIFFERENT SURGICAL TREATMENT PROCEDURES USED IN THE TREATMENT OF LUMBAR SPINAL STENOSIS; RETROSPECTIVE CLINICAL STUDY
}

\author{
(1) Ali Erhan KAYALAR ${ }^{1}$, (1) Orkhan MAMMADKHANLI ${ }^{2}$, (1) Suat CANBAY ${ }^{3}$, (1) Sait NADERI ${ }^{1}$ \\ ${ }^{1}$ Ümraniye Training and Research Hospital, Clinic of Neurosurgery, İstanbul, Turkey \\ ${ }^{2}$ Medical Park Ankara Hospital, Clinic of Neurosurgery, Ankara, Turkey \\ ${ }^{3}$ Yüksek Ihtisas University Faculty of Medicine, Medical Park Ankara Hospital, Clinic of Neurosurgery, Ankara, Turkey
}

\begin{abstract}
Objective: We aimed to compare the clinical results of three different surgical approaches (bilateral decompression via unilateral approach (BDUA), BDUA + fusion with unilateral instrumentation, total laminectomy and fusion with bilateral instrumentation) in the treatment of lumbar spinal stenosis.

Materials and Methods: The clinical and surgical aspects of 51 surgically treated patients with lumbar spinal stenosis were retrospectively reviewed.

Results: Duration of surgery, amount of bleeding, pain assessment visual analogue scale, length of stay (LOS), duration of mobilization, time required for return to work, complications and cost were analyzed. The mean postoperative low back VAS score was calculated to be 7.1 in group $1,8.3$ in group 2, and 8.6 in group 3. Significant decreases were found in the VAS scores of each group ( $p<0.005)$. In group 2 and group 3, delayed mobilization was the main cause of prolonged LOS.

Conclusion: In this study, comparing these three surgical procedures, we evaluated the VAS scores of the low backs and legs of the patients separately, and found no significant difference in the VAS scores of any group. Similarly, durations of surgery, blood loss during surgery, and the time required for return to work make BDUA more advantageous. Presence of severe low back pain and risk of iatrogenic instability may dictate the addition of unilateral fusion and instrumentation to surgery in selected cases.

Keywords: Spinal stenosis, laminectomy, fusion, unilateral instrumentation, decompression
\end{abstract}

\section{INTRODUCTION}

Lumbar spinal stenosis may appear in one or multiple spinal segments, and in central part or in lateral part of the spinal canal. Facet joint hypertrophy, ligamentum flavum hypertrophy, disc degeneration, unstable spine segment, or coexistence of one or more of these may have a role in pathology. Neurogenic claudication is the main symptom in cases not accompanied by significant instability ${ }^{(1)}$.

Surgery is indicated for adequate spinal canal and nerve root decompression. For this purpose, surgical procedures such as total laminectomy unilateral laminotomy, bilateral laminotomies and open door laminoplasty have been performed. Fusion can be added to decompression in cases with existing preoperative instability and in cases with risk of iatrogenic instability ${ }^{(2,3)}$.
Bilateral decompression via a unilateral approach (BDUA) was initially described by Young et al. ${ }^{(4)}$ and then was modified by McCulloch ${ }^{(5)}$. In this technique, the risk of iatrogenic instability is reduced by preserving the facet joints.

Unilateral stabilization and contralateral decompression were considered to be effective in terms of operation time, surgical complications, and patient benefit visual analogue scale in comparison to other surgical techniques for the treatment of lumbar spinal stenosis.

There is no doubt that a fusion procedure should be performed in the presence of accompanying instability. However, in spinal stenosis cases without instability and spondylolisthesis less than grade 1 , the role of spinal fusion is controversial. This is so because spinal instrumentation in degenerative spine may cause adjacent segment degeneration and disease. Therefore, procedures such as bilateral foraminotomy, BDUA, and

This study was presented in the "Unilateral Instrumentation-fusion and Bilateral Decompressive Surgery in Degenerative Lumbar Spinal Stenosis via Unilateral Approach; Advantages and Comparison to Different Approaches" XVI. World Congress of Neurosurgery, Program book, 242, as an oral presentation in İstanbul, Turkey in August 2017.

Address for Correspondence: Orkhan Mammadkhanli, Medical Park Ankara Hospital, Clinic of Neurosurgery, Ankara, Turkey

Phone: +90 5389438813 E-mail: dr.mammadkhanli@gmail.com Received: 06.11.2019

Accepted: 10.01.2020 ORCID: orcid.org/0000-0003-3299-4196 
turkishspine

endoscopic decompression, whereby adequate decompression can be ensured without creating iatrogenic instability, by using less invasive methods, has become popular ${ }^{(6,7)}$. The objective of this study is to compare the efficacy of BDUA with the efficacy of stabilization with decompression.

\section{MATERIALS AND METHODS}

The data of 51 patients operated with three different surgical procedures due to lumbar spinal stenosis were analyzed retrospectively. Informed consent was obtained from the patients.

Inclusion Criteria: Patients with spinal stenosis, who had no instability and spondylolisthesis less than grade 1 in their preoperative imaging tests; who had no concomitant pathologies such as inflammation and malignancy; and who had not undergone spinal surgery in the past, were enrolled in the study.

Exclusion Criteria: Patients with spinal stenosis, who had instability and spondylolisthesis higher than grade 1 in their preoperative imaging tests; who had pathologies such as inflammation and malignancy; and who had a history of spinal surgery, were excluded from the study.

\section{Groups}

Group 1 consisted of patients treated with BDUA; when we noticed instability of facet joints or removed more than $50 \%$ of facet joints, then we added instrumental fusion during surgery. Group 2 consisted of patients treated with BDUA plus instrumented fusion via a unilateral approach; and group 3 consisted of patients treated with total laminectomy and bilateral instrumentation as well as fusion.

Patients underwent lumbar flexion and extension radiographs in the postoperative period, in the $2^{\text {nd }}$ month, $6^{\text {th }}$ month, and 1 year after the surgery. We considered the patient as unstable when there were both back pain and the vertebral slippage.

\section{Surgical Procedure}

All of them were operated by posterior midline approach. It was performed unilaterally in group 1 and 2. In group 3, we used bilateral subperiosteal dissection as an approach. We used microscope (Zeiss).

\section{Group 1: BDUA}

All the surgical operations were performed under general anesthesia when the patients were placed in the prone position. Surgery was initiated from the side where the patient's complaints were dominant; and in patients with no findings regarding the sides, surgery was initiated from the side where stenosis was greater according to the lumbar computed tomography (CT) or magnetic resonance imaging (MRI) images. The bases of the spinous process as well as the upper and lower laminae were removed up to the free edge of the hypertrophic ligamentum, using a high-speed burr. The operating table was tilted to the opposite side so that the angle of the microscope faced towards to the other side. In consequence of these maneuvers, an angle of about $60^{\circ}$ to $70^{\circ}$ was achieved. After the removal of the opposite side and the spinous process, the ligamentum flavum was excised. In this way, decompression was performed on the both sides under a microscope, and then the operation was ended (Figure 1-2).

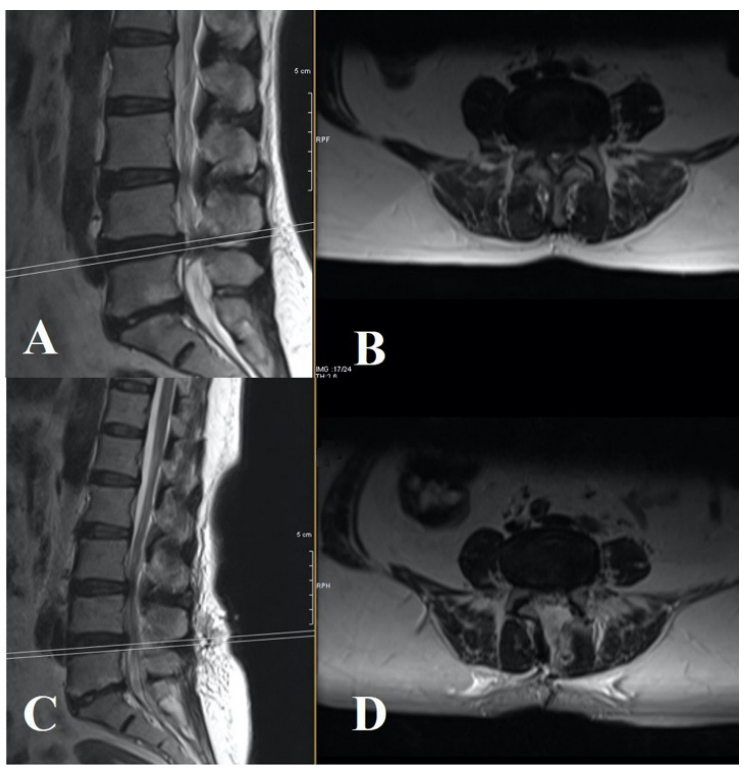

Figure 1. MR images of group 1

A. Preoperative Sagittal T2-weighted MR imaging showing the level of spinal stenosis

B. Preoperative Axial T2-weighted MR imaging showing narrowing spinal canal

C. Postoperative Sagittal T2-weighted MR imaging of patients

D. Postoperative Axial T2-weighted MR imaging showing bilateral decompression of spinal canal via a unilateral approach

MR: Magnetic resonance

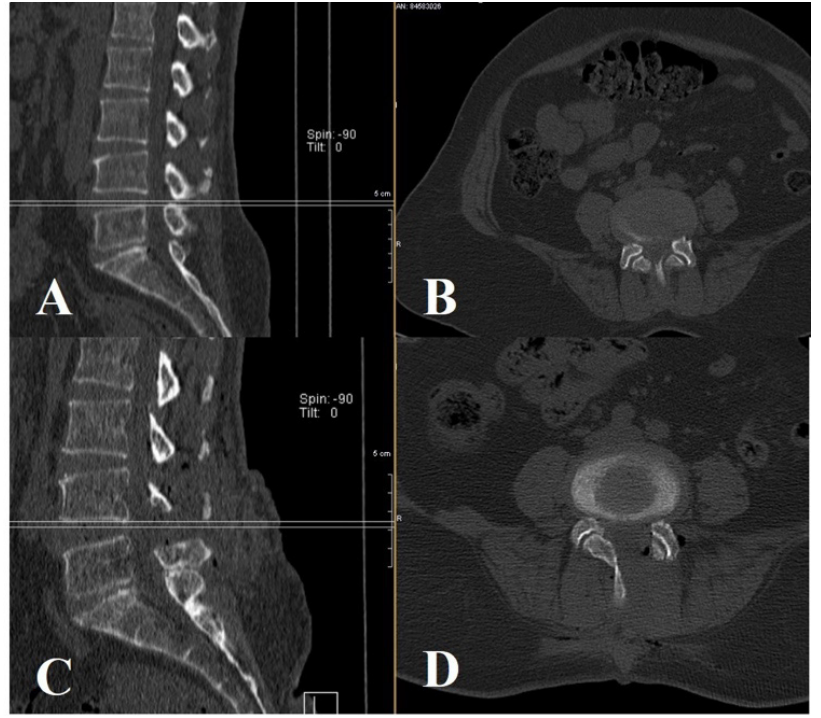

Figure 2. CT images of group 1

A. Preoperative Sagittal CT showing the level of spinal stenosis

B. Preoperative axial $\mathrm{CT}$ showing narrow spinal canal

C. Postoperative Sagittal CT demonstrating the level of decompression

D. Postoperative Axial CT showing bilateral decompression of spinal canal via a unilateral approach (bone window)

$\mathrm{CT}$ : Computed tomography 


\section{Group 2: BDUA + Fusion with Unilateral Instrumentation}

In this group, transpedicular polyaxial screws were placed under fluoroscopy to each related vertebra. After that, a BDUA was performed. After BDUA, autogenous bone grafts were used for fusion. The bone grafts were placed on the lateral sides of the system and outside of the rod by decorticating the bone structures (Figure 3-4).

\section{Group 3: Total Laminectomy and Fusion with Bilateral} Instrumentation

In this group, after exposure, transpedicular polyaxial screws were placed under fluoroscopy to each vertebra on both sides. Total laminectomy was then performed on the preoperatively determined stenotic segments using a Kerrison Ronguer and high-speed drill under a microscope. After the decompression, the screws were fixed with rods. Autogenous bone grafts were used for fusion. The bone grafts were placed on the lateral sides of the system and outside of the rods by decorticating the bone structures (Figure 5-6).

\section{RESULTS}

Duration of surgery, amount of bleeding, pain assessment (VAS), length of stay (LOS), duration of mobilization, time required for return to work, complications and cost were analyzed.

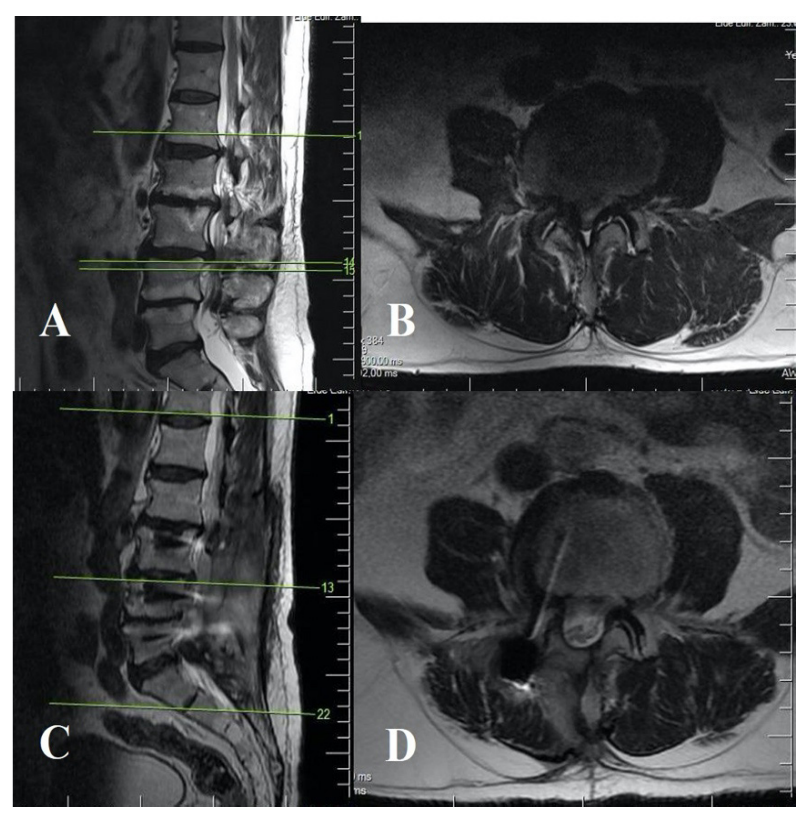

Figure 3. MR images of group 2

A. Preoperative Sagittal T2-weighted MR imaging showing the level of spinal stenosis at the level L3-4

B. Preoperative Axial T2-weighted MR imaging showing ligamentum flavum hypertrophy

C. Postoperative Sagittal T2-weighted MR imaging demonstrating laminectomy defect

D. Postoperative Axial T2-weighted MR imaging showing bilateral decompression and instrumentation via a unilateral approach

MR: Magnetic resonance

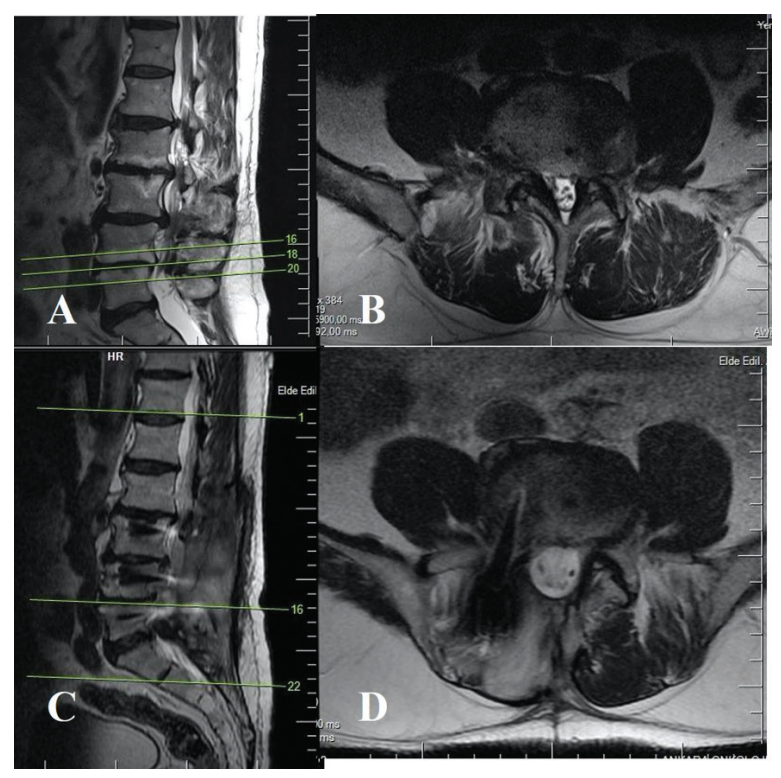

Figure 4. MR images of group 2

A. Preoperative Sagittal T2-weighted MR imaging the same patient showing the level of spinal stenosis at the level L4-5

B. Preoperative Axial T2-weighted MR imaging showing narrowing spinal canal

C. Postoperative Sagittal T2-weighted MR imaging demonstrating level of decompression

D. Postoperative Axial T2-weighted MR imaging showing bilateral decompression and instrumentation via a unilateral approach

MR: Magnetic resonance

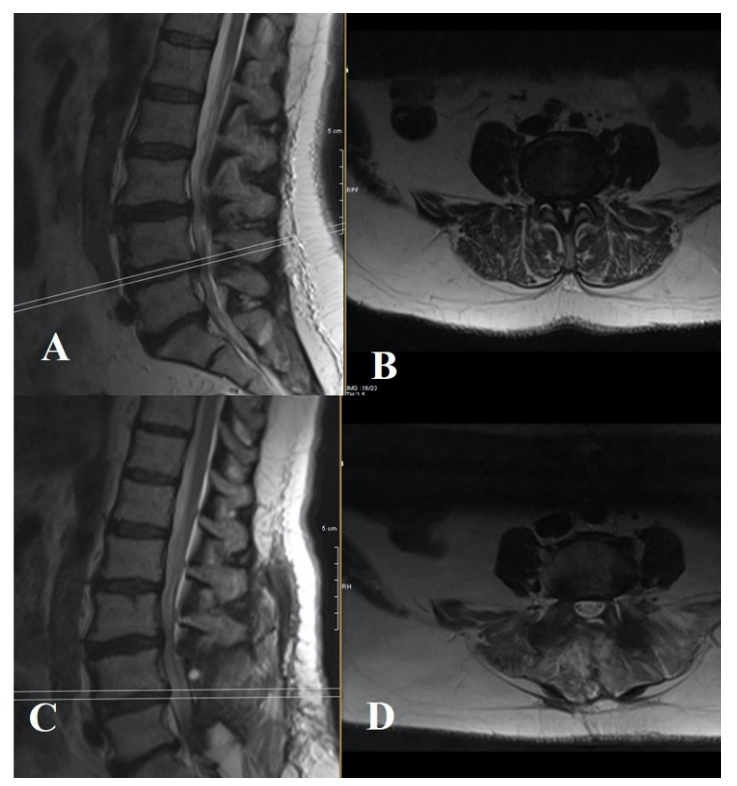

Figure 5. MR images of group 3

A. Preoperative Sagittal T2-weighted MR imaging showing the level of spinal stenosis

B. Preoperative Axial T2-weighted MR imaging showing narrowing spinal canal

C. Postoperative Sagittal T2-weighted MR imaging demonstrating laminectomy defect

D. Postoperative Axial T2-weighted MR imaging showing decompression of spinal canal

MR: Magnetic resonance 
turkishspine

The demographic data of the patients are given in Table 1, data regarding the level of surgery are given in Table 2, and the complication rates are given in Table 3.

Duration of surgery: Duration of surgery was defined as duration from skin to skin. The mean duration was observed to be 94.7 minutes in group 1, 105.1 minutes in group 2, and 163.8 minutes in group 3. A significant difference was observed

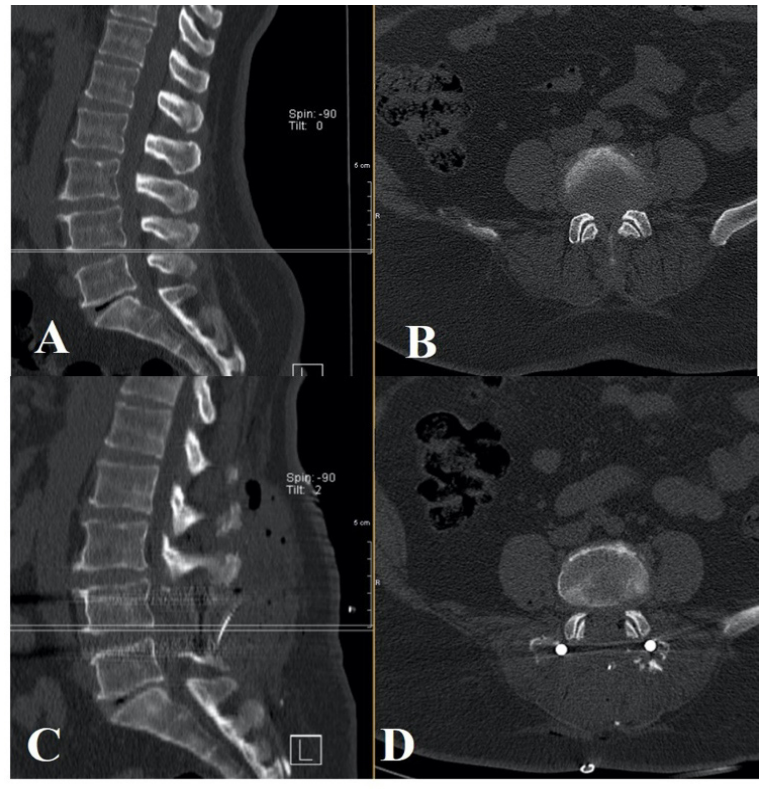

Figure 6. CT images of group 3

A. Preoperative Sagittal CT showing the level of spinal stenosis

B. Preoperative axial CT showing facet joint hypertrophy and narrowing spinal canal

C. Postoperative Sagittal CT demonstrating laminectomy defect

D. Postoperative Axial CT showing decompression of spinal canal and bilateral instrumentation materials

$\mathrm{CT}$ : Computed tomography

Table 1. Demographic data of patients

\begin{tabular}{|c|c|c|c|}
\hline & Group 1 & Group 2 & Group 3 \\
\hline Number of patients & 18 & 16 & 17 \\
\hline Female/Male & $9 / 9$ & $11 / 5$ & $11 / 6$ \\
\hline Age & 63.3 & 65.7 & 55.8 \\
\hline $\begin{array}{l}\text { Mean operation time } \\
(\min )\end{array}$ & 94.7 & 105.1 & 163.8 \\
\hline Mean blood loss (cc) & 70.4 & 75.2 & 275.5 \\
\hline Mean length of stay (day) & 2.1 & 3.1 & 3.6 \\
\hline $\begin{array}{l}\text { Mean follow-up period } \\
\text { (month) }\end{array}$ & 11 & 13 & 14 \\
\hline $\begin{array}{l}\text { Mean Preoperative/ } \\
\text { Postoperative VAS (leg) }\end{array}$ & $8 / 2$ & $8 / 2$ & $8 / 3$ \\
\hline $\begin{array}{l}\text { Mean Preoperative/ } \\
\text { Postoperative VAS (low } \\
\text { back) }\end{array}$ & $7 / 3$ & $8 / 3$ & $8 / 2$ \\
\hline
\end{tabular}

VAS: Visual anolog scale between each of these three groups in terms of duration of surgery $(p<0.005)$.

Amount of bleeding: The amount of bleeding depended to the duration of surgery, the size of the surgical site, and the level of surgical procedure. The mean bleeding rate was $70.4 \mathrm{cc}$ in group 1,75.2 cc in group 2, and $275 \mathrm{cc}$ in group 3 patients. Two patients in group 3 needed 1 unit of erythrocyte suspension (ES) replacement before surgery.

Assessment of pain: Road walking distances as well as the levels of numbness and pain in the legs after walking were assessed. Preoperative and postoperative low back pain and leg pain levels were assessed separately using the VAS. The mean preoperative Leg VAS score was calculated to be 8.3 in group 1 , 8.5 in group 2, and 8.1 in group 3. The mean postoperative low back VAS score was calculated to be 7.1 in group 1,8.3 in group 2 , and 8.6 in group 3. Significant decreases were found in the VAS scores of each group $(p<0.005)$ (Table 1$)$.

Neurological condition: All of the patients have neurogenic claudication preoperatively and it was resolved postoperatively in all of them. Motor examination of 30 out of 51 patients showed $1 / 5$ muscle strength of ankle dorsiflexion. It was improved in 2 months after operation.

Length of stay: The mean LOS in each of the three groups was calculated and assessed. The mean LOS was observed to be 2.1 days in group 1, 3.1 days in group 2, and 3.6 days in

Table 2. Number of patients based on operated levels

\begin{tabular}{llll}
\hline Level & Group 1 & Group 2 & Group 3 \\
\hline L3-4 & 1 & 1 & 3 \\
\hline L4-5 & 11 & 11 & 7 \\
\hline L3-4/4-5 & 4 & 4 & 4 \\
\hline L 3-4/4-5/5-1 & 2 & - & - \\
\hline L 2-3/3-4/4-5 & - & - & 3 \\
\hline
\end{tabular}

Table 3. Complication rates

\begin{tabular}{llll}
\hline Complications & Group 1 & Group 2 & Group 3 \\
\hline Dura defect & 5 & 2 & 2 \\
\hline $\begin{array}{l}\text { Reoperation for dura } \\
\text { repair }\end{array}$ & 1 & - & - \\
\hline $\begin{array}{l}\text { Wound site infection } \\
\text { Postoperative instability }\end{array}$ & 2 & 1 (ab) & 2 (ab + HBO) \\
\hline $\begin{array}{l}\text { Adjacent segment } \\
\text { instrumentation and } \\
\text { decompression }\end{array}$ & - & - & - \\
\hline $\begin{array}{l}\text { Need for } \\
\text { microdiscectomy during } \\
\text { follow-up }\end{array}$ & 1 & 1 & 1 \\
\hline $\begin{array}{l}\text { Instrumentation for the } \\
\text { treatment of iatrogenic } \\
\text { instability }\end{array}$ & 1 & - & - \\
\hline \begin{tabular}{l} 
ab: Antibiotic, HBO: Hyperbaric oxygen \\
\hline
\end{tabular} & & \\
\hline
\end{tabular}


group 3. Routinely antibiotherapy was stopped after the first postoperative day. The number of days of hospitalization that increased due to complications was also considered in the calculation of the days. In group 2 and group 3, delayed mobilization and postoperative routine antibiotherapy were the main causes of prolonged LOS.

Mobilization timing: In group 1 and group 2, early mobilization was performed 6 hours after the surgery, and the patients were discharged the next day. Group 3 patients were mobilized the next morning, and they were then discharged after antibiotherapy. All of the patients were mobilized with lumbosacral brace. The mobilization was unassisted. All of them received physical therapy for their abdominal and spine muscles 6 weeks after surgery.

Complications: The most common complications appeared as a screw malposition, dura defect, and surgical site infection. There were four patients in group 2 and four patients in group 3 with a screw malposition. None of them needed any operation since all of them were asymptomatic. The possibility of screw malposition increased depending on the number of screws used. The number of dural defects changed depending on the increase in the degree of stenosis of the patients, and increased depending on the number of decompressed levels. Surgical site infection increased depending on the increases in the duration of surgery, the amount of bleeding, blood replacement, and the size of the surgical site.

Group 1: Dura defect occurred in five patients, four of whom benefited from perioperative dura repair and one of whom was re-operated after 1 week for dura repair. One patient was given foraminal steroid injection due to leg pain after the $3^{\text {rd }}$ month control examination. In one patient, discectomy was initially performed after the control lumber MRI performed due to pain suffered in the follow-up period; and then instrumentation was made due to the development of iatrogenic instability. Surgical operation was recommended to one of the patients due to postoperative instability, but the patient rejected it, and then physical therapy rehabilitation was recommended (There was a minimal slippage on postoperative $\mathrm{X}$-ray compared to the preoperative films. Also, patient had a back pain and was considered as unstable. Pain was relieved after physical therapy)

Group 2: Two patients had perioperative dura defect and were treated during surgery. One patient was re-hospitalized due to wound site discharge and was given intravenous antibiotic therapy for a period of 10 days due to superficial wound infection. Upon the development of instability during followup period, physical therapy was recommended to one patient, who is currently followed up. The condition of one patient was evaluated with MRI due to the increased pain during the followup examinations, and then microdiscectomy was performed.

Group 3: In two patients, perioperative dura defect developed and was treated during surgery. Since a screw fracture was detected in one patient during the follow-up examination, the instrument was removed and then screw fixation was not repeated. Due to adjacent segment disease development detected during the follow-up examination of one patient, the instrument was extended to the upper level and total laminectomy was performed for the adjacent stenotic segment. Two patients were re-hospitalized due to wound site discharge and were given antibiotic therapy for a period of 10 days and 15 sessions of hyperbaric oxygen therapy. Since screw malposition was detected in the postoperative $\mathrm{CT}$ of one patient, he was reoperated and the screw was corrected the same day.

Cost: Considering the duration of surgery, LOS, possibility of need for blood transfusion, instrument materials used in surgery, possible complications and additional procedures to be performed to correct them, the cost-height ranking was thought to be group $3>2>1$.

Length of follow-up: After their discharge, patients were invited for control examinations to be performed on the $7^{\text {th }}$ day for wound examination and for the removal of the sutures, and in the $3^{\text {rd }}$ and $12^{\text {th }}$ months for pain assessment. The mean followup periods were 11,13 and 14 months for group 1, group 2 and group 3 , respectively.

\section{DISCUSSION}

The objective of surgery for lumbar spinal canal stenosis is the restoration of spinal canal width. Traditional treatment of spinal stenosis is extensive laminectomy, medial laminectomy or total laminectomy ${ }^{(1)}$. However, aggressive decompression may lead to spinal instability. Therefore, many surgeons add fusion to decompression ${ }^{(8,9)}$.

Lumbar spinal fusion may be associated with pseudoarthrosis and adjacent segment disease in long-term. This makes spinal fusion procedure controversial. In this sense, the importance of minimally invasive surgical procedures for the decompression of spinal stenosis has increased. BDUA has been developed for this purpose and has taken its place as an effective option in the treatment of spinal stenosis ${ }^{(10,11)}$. We checked the existence of either loosening or pseudoarthrosis based on the lumbar flexion and extension $\mathrm{X}$-ray, which were performed in the $2^{\text {nd }}$ month, $6^{\text {th }}$ month, and a year after surgery. None of the patients developed screw loosening and pseudoarthrosis.

In classical extensive laminectomy, supraspinous and interspinous ligament complexes may be destroyed, resulting in iatrogenic spinal instability ${ }^{(12)}$. Spondylisthesis may progress as a consequence of the removal of more than $50 \%$ of the facet joints ${ }^{(2)}$. In BDUA, a significant portion of this ligament complex and facet joints are preserved. This surgical technique reduces the risk of instability; and therefore, does not require the addition of fusion to surgery ${ }^{(9)}$.

In the literature, good clinical results were reported after BDUA ( $87 \%$ success in a 9-month follow-up, and $82 \%$ in a one-year follow-up, $70-88 \%$ in an 18 -month follow-up, $67 \%$ in a twoyear follow-up, and $68 \%$ in a four-year follow-up). As the follow-up periods of studies prolong, a decrease in success draws attention ${ }^{(13)}$. 
Cavuşoğlu et al.(14) found the patient's satisfaction rate to be $94 \%$ and the recovery rate to be $96 \%$ during the 18 -24-month follow-up periods of patients with BDUA. In their study comparing clinical and radiological results of BDUA and classical laminectomy, Yaman et al. ${ }^{(15)}$ found differences in VAS scores of leg pain in the postoperative $6^{\text {th }}$ and $12^{\text {th }}$ months. However, low back pain VAS scores in patients with BDUA were found to be significantly lower. In their randomized clinical study comparing BDUA with decompression and involving 79 patients, Choi et al. ${ }^{(16)}$ showed that BDUA was as effective as open decompression in the improvement of ODI scores. In our study, VAS was used to determine patient's satisfaction. The mean VAS change of all these three groups was calculated to be between 60 and $80 \%$.

Park et al. ${ }^{(17)}$ compared the patients that they treated with ipsilateral and contralateral canal decompression by using unilateral laminectomy. In their study, the improvement rate of VAS was $75.4 \%$ for the ipsilateral side and $73.7 \%$ for the contralateral side of each leg. No significant difference was found between the two sides when they were compared with each other.

Another advantage of BDUA is that the paravertebral muscles open unilaterally. Radiological and electromyography findings of atrophy that develops in consequence of bilateral opening and retraction of the paraspinal muscles have been shown in a large number of studies. Unilateral and more limited retraction of BDUA allows for more preservation of the paraspinal muscles ${ }^{(18)}$. Similarly, less blood loss is observed in BDUA. Krut'ko ${ }^{(19)}$ found less blood loss in BDUA procedure compared to blood loss in the standard technique. One of the advantages of this procedure is that less muscle is detached, and less blood loss is observed in minimally invasive techniques as a result of more limited resections. In the study carried out by Cavuşoğlu et al.(14), transfusion of ES was required for some patients in the classical laminectomy group. However, transfusion was not performed in patients in the BDUA group. In our study, blood loss was measured in each of the three groups. The mean blood loss was 70cc in group 1 and group 2, and over $200 \mathrm{cc}$ in group 3.

In the literature, durotomy during laminectomy has been reported to be in rates ranging from 5 to $15 \%$. In their study involving 40 patients, Cavuşoğlu et al.(14) reported three durotomy complications in the classical laminectomy group, and two in the BDUA group. This rate ranges from 3 to $5 \%$ in BDUA. In the study carried out by Park et al. ${ }^{(17)}$, this rate was $5.1 \%$. Durotomy is a fearful complication for surgeons, but in the BDUA procedure and similar minimally invasive approaches, surgeons work through a smaller window; and therefore, there is no significant difference in durotomy rates compared to rates in classical laminectomy. In our study, dural tear rate was about $25 \%$ in group 1, 12,5 \% in group 2,-11,7 \% in group 3 (group 1five patients, group 2 -two patients, and group 3 -two patients). As another advantage, adjacent segment disease does not develop in BDUA. As is known, adjacent segment degeneration and adjacent segment disease may develop after stabilization in degenerative cases ${ }^{(20,21)}$. This condition may require surgery after some time. This means both increased complication and re-operation can increase the total $\cos ^{(9,22)}$. In current series, adjacent segment disease was observed in group 1 and group 2 . One patient in group 3 was operated due to adjacent segment disease.

Therefore, total laminectomy and bilateral decompression are losing their popularity with each passing day.

As an alternative, BDUA can be performed with intent to avoid bilateral dissection and provide stabilization in patients with low back pain due to degenerative spine disorders. With this procedure, results equivalent to those in bilateral intervention have been reported ${ }^{(23)}$. The instrumentation was compared, and unilateral stabilization was found to be advantageous in terms of the duration of surgery, cost and complication (24).

In addition, Mao et al. ${ }^{(25)}$ revealed that unilateral stabilization was less rigid than bilateral stabilization, and therefore, led to less adjacent segment degeneration.

When we analyzed our case series, we found that the BDUA procedure was more successful, in many ways than the classic methods using bilateral decompression and stabilization, particularly in patients with neurogenic claudication and leg pain. When considering complication rates, LOS, and additional treatment requirements in follow-up periods, we found BDUA to be an adequate treatment procedure for appropriate indications. When we compared our patients treated with unilateral screw fixation in group 2 with other patients, BDUA appeared to be the right treatment option for patients with appropriate indications because it involved less instrument materials than those used in the classical procedure, displayed lower duration of surgery rates, shorter hospital stay, and less complication, and there was a decrease in pain symptoms at similar rates.

\section{CONCLUSION}

Lumbar spinal stenosis is among a group of diseases that we usually treat with surgery in spine surgery practice. The surgical treatment options include simple unilateral lumbar decompression, unilateral decompression plus unilateral fusion, bilateral decompression, and bilateral fusion. In this study, comparing these three surgical procedures, we evaluated the VAS scores of the low backs and legs of the patients separately, and we found no significant difference in the VAS scores of any group. Similarly, durations of surgery, blood loss during surgery, and the time required for return to work make BDUA more advantageous. The presence of severe low back pain and risk of iatrogenic instability may dictate the addition of unilateral fusion and instrumentation to surgery in selected cases.

\section{Ethics}

Ethics Committee Approval: Ethical approval have not been taken for the retrospective study. 
Informed Consent: Informed consent was obtained from the patients.

\section{Authorship Contributions}

Surgical and Medical Practices: S.C., Concept: S.N., Design: O.M., Data Collection or Processing: A.E.K., Analysis or Interpretation: S.N., Literature Search: A.E.K., Writing: S.C.

Conflict of Interest: No conflict of interest was declared by the authors.

Financial Disclosure: The authors declared that this study received no financial support.

\section{REFERENCES}

1. Kayalar AE, Onen MR, Gerilmez A, Naderi S. A Cost-Effectiveness Analysis of Bilateral Decompression via Unilateral Approach versus Instrumented Total Laminectomy and Fusion for Lumbar Spinal Stenosis. Turk Neurosurg. 2019;29:643-50.

2. Phan K, Mobbs RJ. Minimally invasive versus open laminectomy for lumbar stenosis: a systematic review and meta-analysis. Spine (Phila Pa 1976). 2016;41:E91-E100.

3. Usman M1, Ali M, Khanzada K, Ishaq M, Naeem-ul-Haq, Aman R, et al. Unilateral approach for bilateral decompression of lumbar spinal stenosis: a minimal invasive surgery. J Coll Physicians Surg Pak. 2013;23:852-6.

4. Young S, Veerapen R, O'Laoire SA. Relief of lumbar canal stenos is using multi level subarticular fenestrations as an alternative to wide laminectomy: preliminary report. Neurosurgery. 1988;23:628-33.

5. McCulloch JA. Microsurgical Spinal Laminotomies in The Adult Spine: Principles and Practice. J.W. Frymoyer, ed. New York: RavenPress, Ltd., 1991

6. Aryanpur J, Ducker T. Multilevel lumbar laminotomies: An alternative to laminectomy in thetreatment of lumbar stenosis. Neurosurgery. 1990;26:429-32; discussion 433.

7. Chatani K. A novel surgical approach to the lumbar spine in volving hemilateral split-off of the spinous process to preserve the multifidus muscle: technical note. J Neurosurg Spine. 2016;24:694-9.

8. Johnsson KE, Willner S, Johnsson K. Postoperative instability after decompression for lumbar spinal stenosis. Spine (Phila Pa 1976). 1986;11:107-10.

9. Katz JN, Lipson SJ, Lew RA, Grobler LJ, Weinstein JN, Brick GW, et al. Lumbar laminectomy alone or with instrumented or noninstrumented arthrodesis in degenerative lumbar spinal stenosis. Patient selection, costs, and surgical outcomes. Spine (Phila Pa 1976). 1997;22:1123-31.

10. Detwiler PW, Spetzler CB, Taylor SB, Crawford NR, Porter RW, Sonntag VK. Biomechanical comparison of facet-sparing laminectomy and Christmastree laminectomy. J Neurosurg. 2003;99(2 Suppl):214-20.

11. Kleeman TJ, Hiscoe AC, Berg EE. Patient out comes after minimally destabilizing lumbar stenosis decompression: the "Port-Hole" technique. Spine (Phila Pa 1976). 2000;25:865-70.
12. Tuite GF, Stern JD, Doran SE, Papadopoulos SM, McGillicuddy JE, Oyedijo DI, et al. Outcome after laminectomy for lumbar spinal stenosis: Part I: Clinical correlations. J Neurosurg. 1994;81:699-706.

13. Thome C, Zevgaridis D, Leheta O, Bazner H, PocklerSchoniger C, Wohrle J, et al. Outcome after less-invasive decompression of lumbar spinal stenosis: a randomized comparison of unilateral laminotomy, bilateral laminotomy, and laminectomy. J Neurosurg Spine. 2005;3:129-41.

14. Cavuşoğlu H, Türkmenoğlu O, Kaya RA, Tuncer C, Colak I, Sahin Y, et al. Efficacy of unilateral laminectomy for bilateral decompression in lumbar spinal stenosis. Turk Neurosurg. 2007;17:100-8.

15. Yaman O, Ozdemir N, Dagli AT, Acar E, Dalbayrak S, Temiz C. A Comparison of Bilateral Decompression via Unilateral Approach and Classic Laminectomy in Patients with Lumbar Spinal Stenosis: A retrospective Clinical Study. Turk Neurosurg. 2015;25:239-45.

16. Choi WS, Oh CH, Ji GY, Shin SC, Lee JB, Park DH, et al. Spinal canal morphology and clinical outcomes of microsurgical bilateral decompression via a unilateral approach for lumbar spinal canal stenosis. Eur Spine. J 2014;23:991-8.

17. Park WB, Hong JT, Lee SW, Sung JH, Yang SH, Kim IS. Clinical and Radiological Comparison between Ipsilateral and Contralateral Side Canal Decompression Using an Unilateral Laminotomy Approach. Korean J Spine. 2016;13:41-6.

18. Mayer TG, Vanharanta H, Gatchel RJ, Mooney V, Barnes D, Judge L, et al. Comparison of CT scan muscle measurements and isokinetic trunk strength in postoperative patients. Spine (Phila Pa 1976). 1989;14:33-6.

19. Krut'ko AV. Results of decompressive-stabilizing procedures via unilateral approach in lumbar spinal stenosis. Zh Vopr Neirokhir Im N N Burdenko. 2012;76:33-40.

20. Ha K-Y, Schendel MJ, Lewis JL, Ogilvie JW. Effect of immobilization and configuration on lumbar adjacent-segment biomechanics. J Spinal Disord. 1993;6:99-105.

21. Shono Y, Kaneda K, Abumi K, McAfee PC, Cunningham BW. Stability of posterior spinal instrumentation and its effects on adjacent motion segments in the lumbosacral spine. Spine (Phila Pa 1976). 1998;23:1550-8.

22. Kuntz KM, Snider RK, Weinstein JN, Pope MH, Katz JN. Costeffectiveness of fusion with and without instrumentation for patients with degenerative spondylolisthesis and spinal stenosis. Spine (Phila Pa 1976). 2000;25:1132-9.

23. Kabins MB, Weinstein JN, Spratt KF, Found EM, Goel VK, Woody J, et al. Isolated L4-L5 fusions using the variable screw placement system: Unilateral versus bilateral. J Spinal Disord. 1992;5:39-49.

24. Fernández-Fairen M, Sala P, Ramírez H, Gil J. A prospective randomized study of unilateral versus bilateral instrumented posterolateral lumbar fusion in degenerative spondylolisthesis. Spine (Phila Pa 1976). 2007;32:395-401.

25. Mao L, Chen GD, Xu XM, Guo Z, Yang HL. Comparison of lumbar interbody fusion performed with unilateral or bilateral pedicle screw. Orthopedics. 2013;36:e489-93. 